Table 1. Pre- and post-treatment laboratuary and clinical findings.

\begin{tabular}{lccc}
\hline & Pre-treatment & Post-treatment & P value \\
\hline ESR $(\mathrm{mm} / \mathrm{h})$ & $42.45 \pm 28.88$ & $17.24 \pm 11.31$ & $<0.001^{*}$ \\
CRP $(\mathrm{mg} / \mathrm{L})$ & $24.72 \pm 35.32$ & $5.37 \pm 6.5$ & $0.004^{\star}$ \\
Mass Size $(\mathrm{mm})$ & $36.94 \pm 16.40$ & $10.79 \pm 15.01$ & $<0.001^{*}$ \\
Fistula $(\mathrm{n})$ & $15 / 33(45 \%)$ & $2 / 33(6 \%)$ & $<0.001^{\star *}$ \\
Nipple discharge $(\mathrm{n})$ & $17 / 33(52 \%)$ & $1 / 33(3 \%)$ & $<0.001^{\star *}$ \\
\hline
\end{tabular}

ESR: Erythrocyte sedimentation rate; CRP: C-reactive protein; ${ }^{*}$ Paired T Test; ${ }^{\star \star}$ Chi-Square test.

Conclusion: Methotrexate has so far been added to IGM treatment in order to decrease steroid dosage or to treat relapses, and it has been reported to be effective in case study and a limited number of studies with few patients $[2,4,5]$. Steroid + methotrexate treatment used by us in patients with IGM, which is a rare disease and for which no consensus exists regarding the treatment protocol, is effective and reliable in providing clinical improvement and long-term remission. Therefore, this treatment appears to be successful owing to long-term remission outcomes and very low relapse rates, without the patients having to undergo a surgical procedure and experience the associated anxiety and complications.

References:

[1] Kessler, E. and Y. Wolloch, Granulomatous mastitis: a lesion clinically simulating carcinoma. Am J Clin Pathol, 1972. 58(6): p. 642-6.

[2] Schmajuk, G. and M.C. Genovese, First report of idiopathic granulomatous mastitis treated with methotrexate monotherapy. J Rheumatol, 2009. 36(7): p. 1559-60.

[3] Patel, R.A., et al., Idiopathic granulomatous mastitis: case reports and review of literature. J Gen Intern Med, 2010. 25(3): p. 270-3.

[4] Sheybani, F., et al., Treatment for and clinical characteristics of granulomatous mastitis. Obstet Gynecol, 2015. 125(4): p. 801-7.

[5] Aghajanzadeh, M., et al., Granulomatous mastitis: Presentations, diagnosis, treatment and outcome in 206 patients from the north of Iran. Breast, 2015. 24(4): p. 456-60.

Disclosure of Interests: None declared

DOI: 10.1136/annrheumdis-2020-eular.679

\section{AB1054 CLINICAL CHARACTERISTICS OF PATIENTS WITH UVEITIS FROM AN AUTOIMMUNE OCULAR DISEASE UNIT}

A. Paats ${ }^{1}$, V. Valinotti ${ }^{1}$, J. Coronel ${ }^{1}$, S. Riquelme ${ }^{1}$, N. Colman ${ }^{1} .{ }^{1}$ Clinicas Hospital, Universidad Nacional de Asuncion, Rheumatology, Asunción, Paraguay

Background: The eye, particularly the uvea due to its substantial vascularization, can be a target for various inmune reactions. Etiology is unknown in most cases of inflamatory ocular disease. Ocassionally, ocular symptoms may be the first manifestation of some systemic diseases and its appearence, therefore, can lead us to the diagnosis and institution of treatment that, if performed early, can avoid irreversible sequelae.

Aim: Describe the experience at 12 months of an autoinmune ocular disease unit.

Objectives: to describe the clinical characteristics of patients diagnosed with uveitis and its association with systemic disease.

Methods: Retrospective, descriptive study. We included patients diagnosed with uveitis attending the Autoimmune Eye Disease Unit from January 2019 to December 2019. Qualitative variables were expressed as frequencies and percentages and quantitative variables as means and standard deviation.

Results: A total of 40 patients were included, $72.5 \%$ were women (26/40). Mean age of disease onset was $38 \pm 17.2$ years and the average diagnostic delay was $19.4 \pm 46.8$ months. The most frequent chief complaint was decrease in visual acuity, cited in $43.8 \%$ of the consults $(25 / 57)$. Involvement was bilateral in $55 \%$ of cases $(22 / 40)$. In order of decreasing frequency, diagnosis found were: Anterior uveitis in $47.5 \%$ (19/40), panuveitis in 35\% (14/40), posterior uveitis in $10 \%(4 / 40)$ and intermediate uveitis in $7.5 \%(3 / 40)$. There was a recurrence $(2$ or more episodes of uveitis) in $65.7 \%(25 / 38)$ of patients and $58.8 \%(20 / 34)$ of them presented some sequelae. Prior to their first episode of uveitis, $12.5 \%$ $(5 / 40)$ of patients had already been diagnosed with an autoimmune disease, the most common of which was spondyloarthropathy (3/5). Meanwhile, $33.3 \%$ (13/39) were diagnosed with a systemic disease from their first episode of uveitis. Regarding laboratory tests, $46.4 \%(13 / 28)$ of patients presented acute phase reactants, $13 \%(3 / 23)$ had positive serum antibodies and $41.6 \%(5 / 12)$ were HLA-B27 positive. Concerning treatment, $76.3 \%$ of patients required systemic corticosteroids (29/38) and $75 \%$ received at least one immunosuppressive drug (30/40). Out of this group, $30 \%$ needed a second immunosuppressive drug Response to treatment was good in $63.6 \%$ of patients (21/33), partial in $18.1 \%$ $(6 / 33)$, poor despite treatment in $6 \%(2 / 33)$ and poor due to lack of adherence in $12.1 \%(4 / 33)$

Conclusion: In our cohort, there was a predominance of female, middle-aged patients with bilateral involvement. Anterior uveitis was the most frequent diagnosis. In one-third of patients, the first episode of uveitis led to diagnosis of a systemic disease. Most of our patients presented some type of sequel or local complication and required systemic treatment with corticosteroids and immunosuppressants.

Disclosure of Interests: None declared

DOI: 10.1136/annrheumdis-2020-eular.6592

\section{AB1055 CERTOLIZUMAB PEGOL: A SAFE AND EFFICIENT TREATMENT IN PATIENTS WITH UVEITIS DURING PREGNANCY.}

D. Prieto-Peña ${ }^{1}$, M. Calderón-Goercke ${ }^{1}$, A. Adan ${ }^{2}$, L. Chamorro-López ${ }^{2}$ O. Maiz ${ }^{3}$, J. De Dios-Jiménez Aberásturi ${ }^{4}$, R. Veroz Gonzalez ${ }^{5}$, S. Blanco ${ }^{6}$, J. M. Santos ${ }^{7}$, F. Navarro ${ }^{8}$, A. Gallego ${ }^{9}$, S. González-Suárez ${ }^{10}$, A. Conesa ${ }^{11}$, A. García-Valle ${ }^{12}$, M. Cordero-Coma ${ }^{13}$, N. Pardiñas-Barón ${ }^{14}$, R. DemetrioPablo $^{1}$, V. Calvo-Río ${ }^{1}$, V. M. Mora-Cuesta ${ }^{1}$, S. Castañeda ${ }^{15}$, J. L. Hernández ${ }^{1}$ M. A. González-Gay ${ }^{1}$, R. Blanco ${ }^{1} .{ }^{1}$ Marqués de Valdecilla University Hospital, Santander, Spain; ${ }^{2}$ Hospital Clinic, Barcelona, Spain; ${ }^{3}$ Donostia San Sebastián, Spain; ${ }^{4}$ Txagorritxu, Vitoria-Gasteiz, Spain; ${ }^{5}$ Mérida, Mérida, Spain; ${ }^{6}$ Galdakano, Vizcaya, Spain; ${ }^{7}$ Río Hortega, Valladolid, Spain; ${ }^{8}$ Elche, Alicante, Spain; ${ }^{9}$ Badajoz, Badajoz, Spain; ${ }^{10}$ Cabueñes, Gijón, Spain; ${ }^{11}$ Castellón, Castellón, Spain; ${ }^{12}$ Río Carrión, Palencia, Spain; ${ }^{13}$ León, León, Spain; ${ }^{14}$ Miguel Servet, Zaragoza, Spain; ${ }^{15}$ La Princesa, Madrid, Spain

Background: Anti-TNFa agents are useful in uveitis (1-5). Certolizumab pegol (CZP) differs from other anti-TNFa agents due to its limited placental transfer. Objectives: To assess efficacy and safety of CZP in women with uveitis during pregnancy.

Methods: Multicenter study of women with uveitis under CZP during pregnancy and their neonates.

Results: 14 women (23 eyes); mean age $34.3 \pm 5.5$ yrs (TABLE 1). Pattern of uveitis: 10 anterior, 2 posterior, 1 intermediate, 1 panuveitis. Uveitis was bilateral in 9 and chronic in 7. CZP was started before conception in 10 patients and after in 4. All patients obtained or maintained ocular remission throughout pregnancy (FIGURE). Prednisone was reduced from a mean dose of $21.7 \pm 19.7 \mathrm{mg} / \mathrm{day}$ to $4.1 \pm 3.8 \mathrm{mg} /$ day at 6 months $(p=0.03)$, leading to complete discontinuation in 4 . 15 healthy infants were born. Only 1 woman presented a mild infection. No infections or malformations were found in neonates after a follow-up of 6 months. 6 infants were breastfed and all received scheduled vaccinations without complications (TABLE 2).

TABLE 1.

\begin{tabular}{lllll}
\hline & Age & Underlying disease & Immunosuppressants before CZP & $\begin{array}{l}\text { Combined } \\
\text { treatment }\end{array}$ \\
\hline 1 & 34 & $\mathrm{SpA}$ & MTX, AZA, ADA & AZA \\
2 & 37 & $\mathrm{SpA}$ & MTX, AZA, IFX, ADA, GOLI & \\
3 & 39 & $\mathrm{SpA}$ & AZA, ADA & AZA \\
4 & 46 & $\mathrm{SpA}$ & CyA, ETN, ADA, IFX, GOLI & \\
5 & 32 & SpA & SSZ, ADA & SSZ \\
6 & 36 & SpA & MTX, HCQ, ADA & \\
7 & 40 & SpA & MTX, LFN, HCQ, IFX, ADA, GOLI & HCQ \\
8 & 31 & Idiopathic & MTX, MMF, CyA, ADA & \\
9 & 33 & Idiopathic & MTX, AZA, ADA, ETN & \\
10 & 32 & RA & MTX & AZA \\
11 & 23 & Vogt-Koyanagi-Harada & AZA, ADA & AZA \\
12 & 36 & Juvenil Idiopathic Arthritis & ADA & \\
13 & 32 & Punctate inner choroidopathy & ADA & \\
14 & 29 & Behcet & CyA, IFX, ADA & \\
\hline & & & &
\end{tabular}

TABLE 2.

\begin{tabular}{|c|c|c|c|c|c|c|c|c|}
\hline & Full term pregnancy & Multiple gestation & $\begin{array}{c}\text { Preconception CZP } \\
\text { exposure }\end{array}$ & $\begin{array}{c}\text { Labor } \\
\text { complications }\end{array}$ & Maternal infections & $\begin{array}{c}\text { Neonatal infections }(<6 \mathrm{~m} \\
\text { after birth) }\end{array}$ & $\begin{array}{c}\text { Congenital } \\
\text { malformations }\end{array}$ & $\begin{array}{l}\text { Breast- } \\
\text { feeding }\end{array}$ \\
\hline Neonates, $\mathrm{n} / \mathrm{N}$ & $15 / 15$ & $2 / 15$ & $5 / 15$ & $0 / 15$ & $1 / 15$ & $0 / 15$ & $0 / 15$ & $6 / 15$ \\
\hline
\end{tabular}


Conclusion: CZP seems to be effective and safe in female patients with uveitis during pregnancy and neonates.

References:

[1] Llorenç $V$ et al. Certolizumab Pegol, a New Anti-TNF-a in the Armamentarium against Ocular Inflammation. Ocul Immunol Inflamm. 2016;24(2):167-72. doi: 10.3109/09273948.2014.967779

[2] Urruticoechea-Arana A et al. Efficacy and safety of biological therapy compared to synthetic immunomodulatory drugs or placebo in the treatment of Behçet's disease associated uveitis: a systematic review. Rheumatol Int. 2019 Jan;39(1):47-58. doi: 10.1007/s00296-018-4193-z

[3] Martín-Varillas JL et al. Successful Optimization of Adalimumab Therapy in Refractory Uveitis Due to Behçet's Disease Ophthalmology. 2018 Sep;125(9):1444-1451. doi: 10.1016/j.ophtha.2018.02.020

[4] Santos-Gómez $M$ et al. The effect of biologic therapy different from infliximab or adalimumab in patients with refractory uveitis due to Behçet's disease: results of a multicentre open-label study. Clin Exp Rheumatol. 2016. SepOct;34(6 Suppl 102): S34-S40

[5] Calvo-Río V et al. Golimumab in refractory uveitis related to spondyloarthritis. Multicenter study of 15 patients.Semin Arthritis Rheum. 2016 Aug;46(1):95101. doi: 10.1016/j.semarthrit.2016.03.002

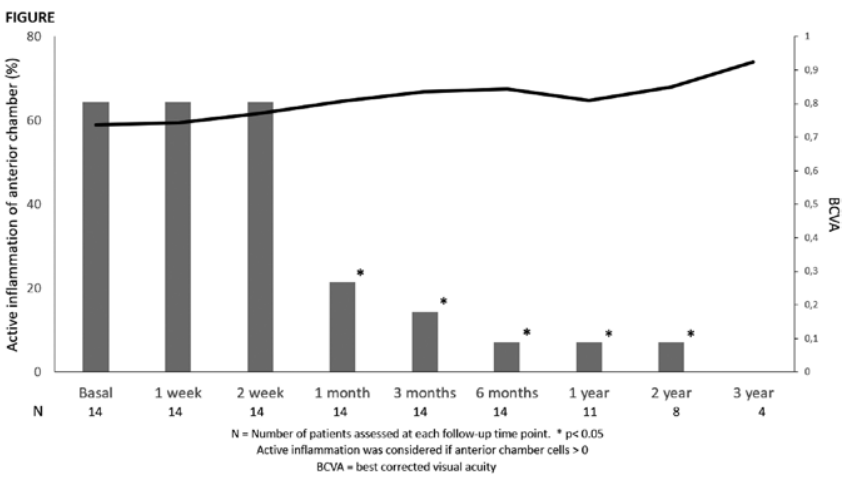

Disclosure of Interests: D. Prieto-Peña: None declared, Monica Calderón-Goercke: None declared, Alfredo Adan: None declared, Lillian Chamorro-López: None declared, Olga Maiz: None declared, JR De Dios-Jiménez Aberásturi: None declared, Raul Veroz Gonzalez: None declared, Soledad Blanco: None declared, José M Santos: None declared, Francisco Navarro: None declared, Adela Gallego: None declared, Senen González-Suárez: None declared, Arantxa Conesa: None declared, Andrea García-Valle: None declared, Miguel Cordero-Coma: None declared, Nieves Pardiñas-Barón: None declared, Rosalía Demetrio-Pablo: None declared, Vanesa Calvo-Río Grant/research support from: MSD and Roche, Speakers bureau: AbbVie, Lilly, Celgene, Grünenthal, UCB Pharma, Victor Manuel Mora-Cuesta: None declared, Santos Castañeda: None declared, J. Luis Hernández: None declared, Miguel A González-Gay Grant/ research support from: Pfizer, Abbvie, MSD, Speakers bureau: Pfizer, Abbvie, MSD, Ricardo Blanco Grant/research support from: AbbVie, MSD, Roche, Consultant of: Abbvie, Eli Lilly, Pfizer, Roche, Bristol-Myers, Janssen, UCB Pharma and MSD, Speakers bureau: Abbvie, Eli Lilly, Pfizer, Roche, Bristol-Myers, Janssen, UCB Pharma. MSD

DOI: 10.1136/annrheumdis-2020-eular.1610

\section{AB1056 SYMPTOMATIC SCLEROSING MESENTERITIS REVEALING ERDHEIM-CHESTER DISEASE: A RARE CONDITION MEDIATED BY BRAF}

J. Razanamahery ${ }^{1}$, S. Humbert ${ }^{2}$, A. Malakhia ${ }^{3}$, J. F. Emile ${ }^{4}$, F. Cohen ${ }^{5}$, J. Haroche ${ }^{5}$, N. Magy-Bertrand ${ }^{1}$. ${ }^{1}$ Besancon University Hospital, Internal Medicine Department, Besancon, France; ${ }^{2}$ Besancon University Hospital, Besancon, France; ${ }^{3}$ Besancon University Hospital, Besancon, France;

${ }^{4}$ Ambroise Paré Hospital, Paris, France; ${ }^{5}$ Internal Medicine Department 2, Paris, France

Background: Sclerosing Mesenteritis (SM) refers to an entire spectrum of digestive inflammatory disorders. Diagnosis is based on imaging showing an increase of fat attenuation displacing bowel loops and is in most cases non-symptomatic. Several conditions (abdominal trauma/surgery, neoplasia, infectious and inflammatory diseases) are responsible for SM (1). Among neoplasia, Erdheim-Chester disease $(E C D)$ is a rare clonal histiocytosis characterized by long bone involvement, peri-nephric fat infiltration and cardio-vascular involvement associated with compatible histology (2). Biopsy is mandatory to confirm tissue infiltration by histiocytes and detect somatic mutation. Almost $80 \%$ of ECDpatients harbor mutation in mitogen activated protein $(M A P)$ kinase pathway especially $B R A F^{V 600 E}$ gene mutation in about $60 \%$ of cases(3). No series of patients presenting both pathologies has been reported. Furthermore, no correlation with $B R A F$ mutation status has been described in patient harboring SM and ECD.

Objectives: To describe the clinical, radiological and mutational status of patients harboring SM and ECD.

Methods: We reviewed the database of patients with histiocytic disorders in Besancon University Hospital. Patient required one abdominal computed tomog raphy showing sclerosing mesenteritis and clinical/histological features of ECD to fulfill the inclusion criteria. All biopsy samples were investigated for mutation of MAP kinase pathway gene.

Results: Four patients suffered from SM and ECD. The median age at the diagnosis of ECD was 68 years old (61-72). All patients described abdomina pain and the mean duration between first symptoms and diagnosis of ECD was 12 months (4-19). The mean CRP level at diagnosis was $40.75 \mathrm{mg} / \mathrm{L}$ (5-117) Two patients were found to have myeloid neoplasms (chronic myelomonocytic leukemia (\#2) and essential thrombocythemia (\#4)) concurrent with ECD diagnosis.

Regarding abdominal computed tomography, all patients had a mesenteric mass associated with hyper-attenuated mesenteric fat and a "fat halo sign". One patient (\#2) had ascites and one had splenomegaly (\#4) but no patient had enlarged lymph nodes. CT also demonstrated peri-nephric fat infiltration ("hairy kidney") (4/4), vascular sheathing of aortic branches (3/4), adrenal hypertrophy (1/4) or ureter dilation (1/4). The mean SUV ${ }_{\max }$ of the mesentery was $7.5(4.1-10.9)$ at diagnosis on $\left({ }^{18} \mathrm{~F}\right)$ - fluorodeoxyglucose-PET. Three patients underwent mesentery fat biopsy and all samples exhibited ECD histology. Regarding mutational status, $75 \%(3 / 4)$ patients had $B R A F^{V 600 E}$ mutation.

After initiation of therapies for ECD (targeted therapies for $3 / 4$ patients), all patients had improvement of digestive symptoms and decreased of SUV $V_{\max }$ on evaluation

${ }^{18}$ FDG-PET during the follow up.

Conclusion: ECD should be investigated in patient with symptomatic SM especially if it is associated with peri-nephric fat infiltration. This condition is rare and might be driven by BRAF gene.

References:

[1] Danford CJ, Lin SC, Wolf JL. Sclerosing Mesenteritis. Am J Gastroenterol. 2019 Jun;114(6):867-73.

[2] Diamond EL, Dagna L, Hyman DM, Cavalli G, Janku F, Estrada-Veras J, et al. Consensus guidelines for the diagnosis and clinical management of Erdheim-Chester disease. Blood. 2014 Jul 24;124(4):483-92.

[3] Haroche J, Cohen-Aubart F, Rollins BJ, Donadieu J, Charlotte F, Idbaih A et al. Histiocytoses: emerging neoplasia behind inflammation. Lancet Oncol. 2017 Feb;18(2):e113-25.

Disclosure of Interests: None declared

DOI: 10.1136/annrheumdis-2020-eular.2447

\section{AB1057 1 SCHNITZLER'S SYNDROME IN THE DIFFERENTIAL DIAGNOSIS OF ADULT STILL'S DISEASE}

S. Salugina ${ }^{1}$, E. Borzova ${ }^{2,3}$, V. Gorodetskiy4, E. Fedorov4. ${ }^{1}$ V.A. Nasonova Research Institute of Rheumatology, Moscow, Russian Federation; ${ }^{2}$ Department of Clinical Genetics, National Research and Clinical Institute of Pediatrics named after Yuri Veltischevat the Pirogov Russian National Research Medical University, Moscow, Russian Federation; ${ }^{3}$ Department of Dermatology and Venereology, I.M. Sechenov First Moscow State Medical University, Moscow, Russian Federation; ${ }^{1}$ V.A. Nasonova Research Institute of Rheumatology, Moscow, Russian Federation

Background: Schnitzler's syndrome (SchS) and adult onset Still disease (AOSD) are currently considered as multifactorial autoinflammatory diseases (MAIDs) and are classified as systemic inflammation with urticarial rash. Clinical similarities between SchS and AOSD (fever, urticarial rash, arthralgias), increased ESR and CRP and the efficacy of IL-1 inhibitors may lead to the diagnostic delay in SchS pts. Testing for monoclonal gammopathy helps establish the diagnosis in SchS pts but is not routinely used in AOSD pts.

Objectives: to examine demographic, clinical and laboratory characteristics, and the therapy of SchS pts in a single rheumatology center.

Methods: 5 SchS patients (2 females, 3 males), aged 32 to 68 , underwent inpatient and outpatient examinations in the rheumatology center. All pts underwent a standard rheumatology examination, including ESR, CRP and M-gradient. 4 pts underwent genetic testing for mutations in NLRP3, TNFRSF1A genes to exclude MAIDs, such as CAPS and TRAPS.

Results: All pts were initially diagnosed with AOSD. The age at onset ranged between 28 and 66 years. Time to diagnosis varied from 2 to 22 years, being within 4 years in 4 of 5 pts. Patients presented with fever (4), urticarial rash (5) and musculoskeletal manifestations (5) (arthralgia in 3, bone pain in 4). Of 2 pts with serositis one presented with pericarditis and another - with pleuritis. Only 1 demonstrated a sore throat and polyneuropathy of the lower extremities. ESR and CRP were increased in all pts, leukocytosis was noted in 4 (Table 1). The 